Journal of

Child Health Care

\title{
Co-producing a digital educational programme for registered children's nurses to improve care of children and young people admitted with self-harm
}

\begin{tabular}{|c|l|}
\hline Journal: & Journal of Child Health Care \\
\hline Manuscript ID & JCHC-2016-0176.R2 \\
\hline Manuscript Type: & Original Article \\
\hline Keyword: & $\begin{array}{l}\text { Nurse Education, Information Technology, Children and Young People } \\
\text { (CYP) participation, Self-harm, Digital Educational Intervention }\end{array}$ \\
\hline & $\begin{array}{l}\text { Despite the increasing prevalence of hospital admissions for self-harm in } \\
\text { children and young people (CYP), there is paucity of registered children's } \\
\text { nurse (rCN) training or involvement of children to improve care for this } \\
\text { often stigmatised patient group. This paper describes a participatory } \\
\text { approach towards using co-production with CYP and rCN to develop a } \\
\text { digital educational programme to improve nurses' knowledge, attitudes and } \\
\text { confidence in caring for CYP with self-harm injuries. }\end{array}$ \\
$\begin{array}{l}\text { Abstract: } \\
\text { A priority-setting workshop with rCNs was used to establish consensus of } \\
\text { information needs. This was followed by an e-learning content } \\
\text { development workshop undertaken with CYP whom had previously } \\
\text { experienced hospital admissions for self-harm injuries. Findings from the } \\
\text { nurse priority-setting workshop identified three educational priorities: } 1 . \\
\text { Knowledge of self-harm; 2. Effective communication and 3. Risk } \\
\text { management. The CYP subsequently developed these topic areas to ensure } \\
\text { the contents and design of the e-learning resource had fidelity by reflecting } \\
\text { the experiences of CYP and needs when cared for in hospital. This paper } \\
\text { illustrates that involving service users to co-develop educational materials } \\
\text { is a feasible and important step in designing educational resources and } \\
\text { ensures the content is relevant, appropriate and sensitive to both the } \\
\text { recipient of care and those responsible for its delivery. }\end{array}$ \\
\hline
\end{tabular}




\begin{abstract}
Despite the increasing prevalence of hospital admissions for self-harm in children and young people (CYP), there is paucity of registered children's nurse $(\mathrm{rCN})$ training or involvement of children to improve care for this often stigmatised patient group. This paper describes a participatory approach towards using co-production with CYP and $\mathrm{rCN}$ to develop a digital educational programme to improve nurses' knowledge, attitudes and confidence in caring for CYP with self-harm injuries. A priority-setting workshop with rCNs was used to establish consensus of information needs. This was followed by an e-learning content development workshop undertaken with CYP whom had previously experienced hospital admissions for self-harm injuries. Findings from the nurse priority-setting workshop identified three educational priorities: 1. Knowledge of self-harm; 2. Effective communication and 3. Risk management. The CYP subsequently developed these topic areas to ensure the contents and design of the elearning resource had fidelity by reflecting the experiences of CYP and needs when cared for in hospital. This paper illustrates that involving service users to co-develop educational materials is a feasible and important step in designing educational resources and ensures the content is relevant, appropriate and sensitive to both the recipient of care and those responsible for its delivery.
\end{abstract}

Keywords: Children and Young People (CYP) participation, Digital Educational Intervention, Information Technology, Nurse Education, Self-harm 


\section{Introduction}

Within Europe, the United Kingdom (UK) has one of the highest rates of self-harm with between $7-14 \%$ of children and young people (CYP) self-harming at some time (Hawton and James, 2005; YoungMinds, 2011). One international comparative community study of 7 countries indicated that prevalence rates for females ranged from $3.6 \%$ (the Netherlands) to $11.8 \%$ (Australia) with England second at 11.1\% (Madge, Hewitt, Hawton et al., 2008) In England, injuries resulting from self-harm lead to over 200,000 Emergency Department attendances annually (Hawton, Bergen, Casey et al., 2007) and CYP have more hospital presentations for self-harm than any other age group (Diggins, Kelley, Cottrell et al., 2017). CYP admitted to hospital wards with self-harm injuries spend significant time being cared for by registered children's nurses (rCNs) who are often the first health professionals encountered by CYPs following a self-harm episode (Anderson and Standen, 2007). However, there is a distinct paucity of mental health training for rCNs, resulting in feelings of unpreparedness to meet the unique and often challenging needs of CYP who self-harm (Horrocks, Hughes, Martin et al., 2005). This has resulted in rCNs expressing a lack of confidence in their ability to work with this often stigmatised patient group (Hodgson, 2016). In addition, previous studies have shown that $\mathrm{rCN}$ attitudes towards patients with mental health problems are not always positive and at times are shown to be stigmatising, resulting in discriminatory behaviour that can impact negatively on the patient's experience and wellbeing (Ross and Goldner, 
2009). There have been urgent calls for $\mathrm{rCN}$ training in mental health and effective provision of care for patients who have self-harmed and present at the emergency department (Hodgson 2016; Coulter, Roberts and Dixon, 2013). CYPs admitted for treatment following self-harm feel they are treated differently from other patients and their views indicate there are still significant improvements needed to change the attitudes and behaviour of health professionals to ensure they receive a high-quality service (Horrocks, Hughes, Martin et al., 2005; McHale et al 2010). There is little evidence to suggest CYP are actively involved in the development of care and consequently their voices remain seldom heard.

Improvements to the way services are delivered is increasingly being influenced by the philosophy of co-production where health professionals and service users work in partnership to improve the patients' experience (Coulter, Roberts and Dixon, 2013; Batalden, Batalden, Margolis, et al., 2015). The co-production concept is broad and can range from service co-planning and co-commissioning, service co-design and codelivery, through to co-assessment, co-monitoring and co-evaluation (Bovaird and Loeffler, 2013). Central to this model of co-involvement is the active contribution of service users that allow services to be tailored whilst also empowering the contribution of front-line health care staff (Needham and Carr, 2009). In the mental health context, co-production has been reported to assist in the delivery of services through the equal 
and reciprocal relationship between professionals, service users, and their families (Slay and Stephens, 2013). This paper extends the co-production philosophy to illustrate an application towards co-producing a digital educational programme with a vulnerable patient group (CYP who self-harm) and rCNs. Due to the unique nature and care needs of these individuals, using a co-production approach with CYP provides an opportunity to promote equity of care by learning 'first-hand' how CYP admitted with self-harm injuries would like to be cared for. This 'bottom up' approach not only facilitates collaboration, it also increases the likelihood of effective care as the strategies prescribed within the resource have come directly from CYP themselves.

A digital educational intervention was identified as an appropriate, convenient and cost efficient method to enable easy access to the training (DoH, 2001; Ruggeri, Farrington, and Brayne 2013) Furthermore, e-learning is seen as a central strategic delivery mechanism being an effective and flexible way to deliver health professional training (DoH, 2001; Lymn, Bath-Hextall and Wharrad, 2008; Windle and Wharrad, 2010). In this paper, we report on the benefits and challenges of the co-production process in this context as well as the themes generated during nurse and CYP workshops.

\section{The Our Care through Our Eyes Study}

The work described in this paper forms part of a wider project that aimed to evaluate the impact of the e-learning material on nursing staff knowledge of self-harm in CYP, 
attitudes and level of confidence to manage care. Further details are reported in the study protocol (Manning, Latif, Carter et al., 2015).

\section{Methods}

\section{Sampling and recruitment}

\section{Nurses priority-setting workshop}

Registered children's nurses were recruited from a large University Hospital NHS Trust located in the Midlands area of England. Nurses were recruited using a theoretical sampling frame to ensure a mix of Agenda for Change (AfC) bandings, children clinical setting (Paediatric Critical Care; Renal and Urology; Medical Short Stay; Children's Assessment Unit; Oncology; Neuro; General Surgery; ENT/Orthodpaedics/Maxillofacio; Medical Long Stay) and time since qualification as a children's nurse. One staff nurse (AfC Band 5) and one junior sister / ward manager (AfC Band 6 or 7) from each of 10 clinical areas plus one matron (AfC Band 8) were identified by their line manager and invited to take part in the study to ensure incorporation of a range of nurse experiences $(\mathrm{n}=19)$.

\section{CYP for e-learning development workshop \\ CYP from Child and Adolescent Mental Health Services (CAMHS) Tier 3 were recruited to take part in a workshop. The inclusion criteria were that CYP were aged 10-}


18 years and that the individuals had been admitted as an inpatient to acute care services within hospital for the treatment of self-harm injuries within the previous 12 months. CYP were excluded if they were deemed by the care team not to be a suitable candidate for the workshop, currently in receipt of acute care for the treatment for self-harm, or if parents/guardians were unwilling to provide consent for their child to take part in the study (those aged 16-18 were allowed to consent for themselves). Eligible CYP were approached by a member of the usual care team. An information sheet was provided to the young person (if $>16$ years) and to their parent / guardian (if $<16$ years) and appropriate time given (about a week) to decide whether to take part in the workshop before informed consent / assent was taken. Seven CYP were identified to be eligible and were approached to take part in the workshop.

\section{Towards a co-production approach}

\section{Nurse priority-setting workshop}

From the 19 nurses invited, 7 attended (37\%) the nurse priority-setting workshop. Participants included four Band 7, one Band 6 and two Band 5 nurses. Participants represented five out of the ten clinical areas (Paediatric Critical Care; Medical Short Stay; Medical Long Stay; Children's Assessment Unit; Oncology), and their average years since qualification was 10.6 years. An adapted Delphi technique was used to establish consensus of nurse information needs and educational topic priorities. This 
involved initial discussion about the challenges of caring for CYP who self-harm, summarising responses and gaining feedback on priority areas. After the first round, a facilitator provided an anonymous summary of the findings. Nurses were then encouraged to revise their earlier answers in the second round, in light of the replies of other members of the group, until consensus was determined. In most cases three iterations are often sufficient to collect the needed information and to reach a consensus (Custer, Scarcella, and Stewart, 1999).

\section{CYP e-learning development workshop}

Conducting research with CYP generates a multitude of ethical challenges that must be identified and addressed (Baxter et al 1998; Alderson 2004). Due to the CYP belonging to a vulnerable group (Owens, Hansford, Sharkey et al., 2016), appropriate safeguards were included to minimise the risk of CYP becoming distressed during the workshop. Separate workshops were undertaken for CYP and nurses to allow the CYP to speak freely and honestly without the fear of offending nurses. CYP were informed that there were no right / wrong answers and that their views are valued, and appropriate professional support was available should the CYP have become distressed.

The CYP workshop was held on a weekend in a local community centre. Four CYP agreed and consented to participate. Participants were all female and had a mean age of 
15 years. It was facilitated by three members of the study team (one of which was a registered mental health nurse) as well as an emotional health and well-being worker from a local NHS Trust. During the workshop, CYP worked in small groups to explore (on flip-charts) what they thought was important to include in a nurse training package. 'Story boards' were used to capture ideas and drawings from the CYP about possible ways to improve the care CYP receive from nurses (Illustration 1). Particular attention was paid to listening and capturing the participant voices. CYP were given $£ 20$ worth of High Street vouchers for taking part in the workshop. All participants provided written informed consent, assent where appropriate, to take part.

\section{Ethical approval}

This study was conducted in accordance with the ethical principles of ICH Good Clinical Practice. Full ethical approval has been received from East Midlands Research Ethics Committee (REC ref: Derby 15/EM/0236), along with research governance clearance from the appropriate National Health Service (NHS) Trust.

\section{Findings}

Nurse priority-setting workshop:

Delphi technique round 1: Exploring nurse experiences and challenges 
The first round of the Delphi technique involved an initial discussion about the challenges of caring for CYP who self-harm. A range of issues were reported demonstrating the need for further nurse training and support. These discussions are summarised in Table 1. The most frequently reported areas of need were more training in risk assessment and supervision. The lack of formal guidelines and perceived lack of resource resulted in feelings of uncertainty over how supervision of CYP should be undertaken and managed. This round of the Delphi exercise also revealed a general lack of knowledge about self-harm and lack of confidence to how to provide care for CYP on the ward.

\section{Delphi technique round 2: Refining initial ideas}

Following the first round, participants were asked to focus on the list of challenges identified and consider what an educational intervention should cover to improve their knowledge, skills and their confidence in providing care to this patient group. Seven topic areas were identified: communication with CYP and families, knowledge of selfharm and pathways of care, supervision, assessing and managing risk, establishing and negotiating boundaries and behaviours, improving the ward environment and resources for CYP.

\section{Delphi technique round 3: Prioritisation of topics}


The final stage of the Delphi exercise involved participants ranking the areas identified in round 2 to allow for prioritisation of topic areas. It was explained that the top 3-4 areas would be developed into a digital education programme. There was consensus that the following four areas would be most useful to develop e-learning:

1. Assessing and managing risk

2. Communication with CYP and families

3. Supervision

4. Knowledge of self-harm and pathways of care

\section{CYP e-learning development workshop}

At the beginning of the workshop, CYP were provided with background information on the purpose of the study and the four priority areas that emerged from the nurse priory setting workshop. This was not to set the agenda, but rather to open up the discussion. It became apparent that these areas resonated closely with the CYP as areas that $\mathrm{rCN}$ could improve. All participants shared their personal experiences of being in hospital to discuss and decide what to include in the digital education programme. Participants were encouraged to self-reflect on their experience in hospital to provide insights into what the training should be focused upon. From initial discussions between the CYP it was felt that the priority themes 'assessing and managing risk' and 'supervision' should be explored under one theme. This created 3 areas for development into the digital education programme: 


\section{Understanding self-harm and care pathways}

To improve nurses' knowledge of self-harm, participants suggested personal biographies with life histories to illustrate the complex picture before presenting to Emergency Departments (ED). They also suggested that nurses must appreciate that CYP tend to have complex social situations and should appreciate the reasons why people self-harm and be aware of care pathways within hospital and following discharge.

\section{Effective communication}

CYP were asked to reflect on their experience of care during their stay in hospital following self-harm. They reported that nurses mainly provide 'physical care' i.e. the care was deemed too 'clinical'. The questions that the nurses asked were perceived to be generic and not appreciative of their emotional state or recent experiences. CYP felt largely neglected due to nurses not speaking to them which led to a general sense of feeling unimportant, misunderstood and isolated. These feelings led the CYP to want to 'hide' how they felt. As such, it was hard for CYP to communicate how they felt during their time on the ward which led to them seeing the nurses as not on the 'same side' as them. The e-learning should therefore emphasise the nurses' responsibility to build up a rapport with CYP without being afraid or avoiding the topic of self-harm. Video clips could be used to illustrate examples of good / poor communication. 
CYP preferred nurses to use a direct approach, and asking open questions when asking about self-harm to foster a culture of openness. They also wanted nurses to appreciate that during admission, CYP were often uncommunicative and not wanting to engage. Nevertheless, although acknowledging this, CYP still preferred nurses to attempt dialogue and not abandon their efforts despite the lack of response.

\section{Assessing risk and managing safety}

Three areas were identified as being important: 1. Risk assessment through appropriate and respectful collaboration; 2. Strategies to reduce risk including distracting the CYP so that they could focus on something positive during their stay in hospital. For example, they saw distraction while on wards as a means to reduce the risk of further self-harm and to manage problematic behaviour often associated with boredom; and 3 . supervising the CYP through developing a sense of partnership with the CYP. CYP emphasised that successful supervision lay in building rapport and creating care plans in partnership.

\section{Discussion}

This paper outlines the development of a digital education programme for $\mathrm{rCNs}$ caring for CYP admitted to hospital with self-harm. Through meaningful engagement with 
rCNs and CYP service users, an evident level of co-production was found to be feasible and the methods used acceptable. Moreover, despite the challenges of participant recruitment, the co-production approach offered unique insights and learning on how to improve care for CYP who self-harm. This study further builds on the evidence base, for example the study by Manikam et al (2016), which illustrates the benefits of coproduction with CYP in healthcare and the different insights patients, public and professionals can offer research and services. In light of calls to make services more responsive to the needs of patients (Dunston et al., 2009; Realpe and Wallace, 2010), we have shown that co-production can be extended to the development of training materials for nurse professionals, and subsequently advocate for its wider application.

Discussions by rCNs focussed on professional concerns and deficits in the provision of care to CYP culminating in four priority learning areas being identified (1-assessing and managing risk, 2-communication with CYP and families, 3-supervision, 4-knowledge of self-harm and pathways of care). Although there are a number of empirical studies have identified deficits in nurses' knowledge and skills in caring for people who self-harm and recommend that further training interventions should be developed (Thompson et al. 2008; Cooke and James, 2009; Conlon and O'Tuathail, 2012), there is little detail as to the content and mode of delivery these should take. Therefore this study has provided 
new insights as to the focus the training should adopt to meet the educational needs of rCNs caring for CYP admitted to hospital with self-harm.

It was evident that CYPs adopted a more appreciative standpoint to exploring and developing the e-learning programme. CYPs used experiential knowledge to offer rich and insightful suggestions on how to improve care and how the e-learning could be made engaging (i.e. through the use of video stories). In this sense, the co-production approach was particularly useful to ensure the CYP voice which was heard and acknowledged and delivered in an appropriate and stimulating format. Through using this approach, insights and recommendations and ways to improve care were made. As such, the resources produced are uniquely placed to address the clearly-defined knowledge gaps reported by nurses. The nurse training programme that was subsequently developed is openly accessible and available via the following link: http://sonet.nottingham.ac.uk/rlos/mentalhealth/octoe/.

Evidence suggests that the attitudes of hospital staff towards individuals who repeatedly self-harm are largely negative and that training can lead to consistent improvements in health professional's attitudes and knowledge (Saunders, Hawton, Fortune et al., 2012). The findings from the 'our care through our eyes study are reported elsewhere (Manning, Carter, Latif et al., 2016). In short, the evaluation found the e-learning 
produced by the co-production approach improved nurse's knowledge, attitudes and confidence. Furthermore, nurses reported being more knowledgeable; having the skills and ability to effectively communicate; and stimulating both a reflection on own practice and of CYP emotional health and wellbeing in a broader context. The elearning method also makes such training sustainable and acceptable given that it can be delivered at low cost to the service provider.

\section{Strengths and limitations of this study}

The e-learning was produced by active involvement of service users and $\mathrm{rCN}$ working on the frontline. In this sense the final resource was sensitive to nurse learning needs and included a strong patient voice. The main challenge was with recruitment both with nurses and CYP. Despite workshops being arranged in the summer months to avoid winter work pressures, staffing pressures were a barrier to participation. Recruitment of CYP was equally challenging reflecting the sensitive nature of self-harm and ethical safeguards needed to ensure CYP were suitable for the workshop. Despite the significant effort and working with CAMHS colleagues to build trust, CYP engagement remained low with no males being recruited. Future lessons could include more attractive incentives, a web based forum to hold 'virtual' workshops or considering on a case-by-case basis CYP who are currently in receipt of acute care for the treatment for self-harm. 


\section{Conclusion}

Despite recruitment challenges, this study illustrates that involving service users to codevelop educational materials for nurses is a feasible and important step in designing educational resources and ensures the contents of the learning material is relevant, appropriate and sensitive to both the recipient of care and those responsible for its delivery.

\section{Authors' contributions}

$\mathrm{JM}, \mathrm{AL}$ and $\mathrm{TC}$ were responsible for the overall development, design and data collection for the study. JLB contributed to the study design and responsible for CYP recruitment. HW led on the development of the e-learning. AL, TC and JM drafted the paper. All authors contributed to editing and approved the final manuscript.

\section{Acknowledgements}

The authors would like to acknowledge and thank all participants who contributed to the development and design of this study. In particular, the Children and Young people who generously provided their time to take part in the study. We would also like to acknowledge all members of the 'Our Care through Our Eyes' study project team: Angela Horsley, Jamie Crew, Joanne Cooper, Damian Wood, Marie Armstrong and Patrick Callaghan. 


\section{Funding Acknowledgement}

This work was funded by the Burdett Trust for Nursing, 1 Curzon Street, London, W1J 5FB (Grant number 531451).

\section{Declaration of Conflicting Interests}

The authors have not declared any competing interests. 


\section{References}

Anderson M, Standen PJ (2007) Attitudes towards suicide among nurses and doctors working with children and young people who self-harm. Journal of Psychiatric and Mental Health Nursing 14(5): $470-477$.

Batalden M, Batalden P, Margolis P, Seid M, Armstrong G, Opipari-Arrigan L and Hartung H (2015) Coproduction of healthcare service. BMJ quality \& safety: doi:10.1136/bmjqs-2015-004315.

Bovaird T, Loeffler E (2013) The role of co-production for better health and wellbeing: Why we need to change. In Loeffler E, Power G, Bovaird T, Hine-Hughes F, eds. Co-production of health and wellbeing in Scotland. Birmingham, UK: Governance International.

Conlon M and O'Tuathail C (2012) Measuring emergency department nurses' attitudes towards deliberate self-harm using the self-harm antipathy scale. International Emergency Nursing 20, 3-13.

Cooke E and James V (2009) A self-harm training needs assessment of school nurses. Journal of Child Health Care 13, 260-274.

Coulter A, Roberts S and Dixon A (2013) Delivering better services for people with long-term conditions: building the house of care. London: The King's Fund. Available at: http://www.kingsfund.org.uk/publications/delivering-better-services-people-long-term-conditions.

Custer RL, Scarcella JA, and Stewart BR (1999) The modified Delphi technique - a rotational modification. Journal of Career and Technical Education. 15(2)

Department of Health (2001) Working Together-Learning Together. A Framework for Lifelong Learning in the NHS. London: Department of Health.

Diggins E, Kelley R, Cottrell D, House A and Owens D (2017) Age-related differences in self-harm presentations and subsequent management of adolescents and young adults at the emergency department. Journal of affective disorders 208: 399-405.

Dunston, R., Lee, A., Boud, D., Brodie, P. and Chiarella, M. (2009) Co-Production and Health System Reform - From Re-Imagining To Re-Making. Australian Journal of Public Administration, 68: 39-52. doi:10.1111/j.1467-8500.2008.00608.x. 
Hawton K, Bergen H, Casey D, et al. (2007) Self-harm in England: a tale of three cities. Multicentre study of self-harm. Social Psychiatry and Psychiatric Epidemiology 42: 513-521. doi:10.1007/s00127-007-0199-7.

Hawton K and James A (2005) Suicide and deliberate self-harm in young people. British Medical Journal 330(7496): 891-894.

Hodgson K (2016) Nurses' attitudes towards patients hospitalised for self-harm. Nursing Standard 30(31): 38-44.

Horrocks J, Hughes J, Martin C, House A, and Owens D (2005) Patient experiences of hospital care following self-harm-a qualitative study. Leeds: University of Leeds.

Manikam L, Shah R, Reed K., Santini G and Lakhanpaul M (2016) Using a co-production prioritization exercise involving South Asian children, young people and their families to identify health priorities requiring further research and public awareness. Health Expect. doi:10.1111/hex.12524

Lymn JS, Bath-Hextall F and Wharrad HJ (2008) 'Pharmacology education for nurse prescribing students-a lesson in reusable learning objects', Biomedcentral Nursing, 7(1): 2.

Manning JC, Carter J, Latif A, Horsley A, Armstrong M, Cooper J, Crew J, Wood D, Callaghan P and Wharrad H (2016) A service-user co-produced digital education programme for acute hospital nurses to improve the care of children and young people that self-harm. Nottingham: University of Nottingham. Available at: http://www.btfn.org.uk/library/directory_listings/346/Our\%20Care\%20Through\%20Our\%20Eyes\%2 0Report.pdf.

Manning JC, Latif A, Carter J, Cooper J, Horsley A, Armstrong M and Wharrad H (2015) 'OurCare through Our Eyes': a mixed-methods, evaluative study of a service-user, co-produced education programme to improve inpatient care of children and young people admitted following self-harm. BMJ open 5(12): p. e009680. 
Madge N, Hewitt A, Hawton K, Wilde E.J.D, Corcoran P, Fekete S et al (2008) Deliberate self-harm within an international community sample of young people: comparative findings from the Child \& Adolescent Self-harm in Europe (CASE) Study. Journal of child Psychology and Psychiatry 49(6): 667-677.

McHale J and Felton A (2010) Self-harm: what's the problem? A literature review of the factors affecting attitudes towards self-harm. Journal of Psychiatric and Mental Health Nursing 17(8): 732740.

Needham C and Carr S (2009) SCIE Research Briefing 31: Co-production: An emerging evidence base for adult social care transformation, London: Social Care Institute for Excellence.

Owens C, Hansford L, Sharkey S, and Ford T (2016) Needs and fears of young people presenting at accident and emergency department following an act of self-harm: secondary analysis of qualitative data. The British Journal of Psychiatry 208(3): 286-291.

Realpe A. and Wallace LM. (2010) What is co-production? London: The Health Foundation.

Ross CA and Goldner EM (2009). Stigma, negative attitudes and discrimination towards mental illness within the nursing profession: a review of the literature. Journal of Psychiatric and Mental Health Nursing 16(6): 558-567.

Ruggeri K, Farrington C and Brayne C (2013) A global model for effective use and evaluation of elearning in health. Telemedicine and e-Health 19(4): 312-321.

Saunders KE, Hawton K, Fortune S and Farrell S (2012) Attitudes and knowledge of clinical staff regarding people who self-harm: a systematic review. Journal of Affective Disorders 139(3): 205-216. Slay J and Stephens L (2013). Co-production in mental health: A literature review. London: new economics foundation.

Thompson AR., Powis J and Carradice A (2008) Community psychiatric nurses' experience of working with people who engage in deliberate self-harm. International Journal of Mental Health Nursing 17, 153-161.

Windle R and Wharrad H (2010) Reusable learning objects in health care education. In Interprofessional e-learning and collaborative work: practices and technologies. Bromage A, 
1

2

3

4

5

6

7

8

9

10

11

12

13

14

15

16

17

18

19

20

21

22

23

24

25

26

27

28

29

30

31

32

33

34

35

36

37

38

39

40

41

42

43

44

45

46

47

48

49

50

51

52

53

54

55

56

57

58

59

60
Clouder L, Thistlethwaite $\mathrm{J}$ and Gordon F. (Eds) Information Science Reference (IGI Global): Hershey, NY. pp. 244-259.

YoungMinds (2011) 100,000 children and young people could be hospitalised due to self-harm by 2020 warns YoungMinds. 5 December. London: YoungMinds. 


\section{Illustration 1: Effective communication storyboard}




Table 1: Experiences of the children's nurses of the challenges of caring for CYP

\begin{tabular}{|l|l|}
\hline Topic area & \multicolumn{1}{|c|}{ Example extracts of the challenges when caring for CYP } \\
\hline Location / environment & $\begin{array}{l}\text { Wards being unsuitable placed when CYP are waiting for a CAMHS } \\
\text { assessment as they are alongside other young people who have more } \\
\text { overt illness }\end{array}$ \\
\hline Risk assessment/ supervision & $\begin{array}{l}\text { Lack of knowledge / skills to make a risk assessment } \\
\text { Unclear as to who is responsible for supervising or providing 1:1 } \\
\text { care while on the ward }\end{array}$ \\
\hline Care needs & $\begin{array}{l}\text { CYP who are on medicines take priority over CYP who self-harm } \\
\text { due to care perceived as 'time critical' } \\
\text { Staff attitudes towards CYP who self-harm }\end{array}$ \\
\hline Care on the ward & $\begin{array}{l}\text { Reports of avoiding conversations with CYP who self-harm for fear } \\
\text { saying something wrong } \\
\text { Lack of confidence to care for this group }\end{array}$ \\
\hline $\begin{array}{l}\text { Review by Child and } \\
\text { Services (CAMHS) }\end{array}$ & $\begin{array}{l}\text { Poor behaviour of CYP } \\
\text { CYP being bored on wards } \\
\text { mean the CYP waiting on the ward for several days }\end{array}$ \\
\hline Family support & $\begin{array}{l}\text { Nurses need support on how to manage parents and families of CYP } \\
\text { who self-harm }\end{array}$ \\
\hline
\end{tabular}

